J Dtsch Dermatol Ges. 2009 December ; 7(12): 1065-1067. doi:10.1111/j.1610-0387.2009.07209.x.

\title{
Cutaneous gamma/delta T-cell lymphoma
}

\author{
Richard Koch ${ }^{1}$, Elaine S. Jaffe ${ }^{2}$, Christian Mensing ${ }^{1}$, Matthias Zeis ${ }^{3}$, Norbert Schmitz ${ }^{3}$, and \\ Christian A. Sander ${ }^{1}$ \\ ${ }^{1}$ Eduard-Arning Clinic for Dermatology and Allergology Asklepios Klinik St. Georg, Hamburg, \\ Germany \\ ${ }^{2}$ Hematopathology Section, Laboratory of Pathology, NCI, Bethesda, USA \\ ${ }^{3}$ Department of Hematology, Asklepios Klinik St. Georg, Hamburg, Germany
}

\section{Summary}

Only 40 cases of primary cutaneous gamma/delta T-cell lymphoma (GD-TCL) have been described. GD-TCL was included as a provisional entity in the WHO-EORTC classification of cutaneous lymphomas in 2005.

GD-TCL often failed to respond to polychemotherapy and radiation therapy and have a poor prognosis with a mean survival of only 15 months. We present a patient treated with surgery, immunomodulatory therapy, and polychemotherapy. He then received hematopoietic stem cell transplantation and has been in complete remission since. Allogeneic stem cell transplantation appears to be a promising therapeutic option for aggressive and generally fatal lymphomas like GD-TCL.

\section{Keywords}

gamma/delta-T-cell-receptor; cutaneous lymphoma; hematopoietic stem cell transplantation

\section{Introduction}

Primary cutaneous gamma-delta T-cell lymphoma is a very uncommon and highly aggressive tumor, resistant to chemotherapy and radiation therapy, and thus with a foreboding outlook. We present a 36-year-old man who was brought into complete remission through allogenic stem cell transplantation.

\section{Case report}

\section{History}

A 36-year-old, hepatitis-C-positive patient with a history of drug addiction visited our clinic for the first time in August 2006. He reported that in March 2006, multiple large, nodular, partly exudative and necrotic tumors had appeared on his right thigh and then spread over his body. Upon admission to the clinic he also reported night sweats and unintentional weight loss of about $7 \mathrm{~kg}$ in 3 months.

\footnotetext{
(C) The Authors

Correspondence to: Dr. med. Richard Koch, Eduard-Arning-Klinik für Dermatologie, und Allergologie, Asklepios Klinik St. Georg, Lohmühlenstraße 5, D-20099 Hamburg, Tel.: +49-40-18-1885-4142, Fax: +49-40-18-1885-3919, ri.koch@ asklepios.com.

Conflict of interest

None.
} 


\section{Clinical presentation}

The patient was $184 \mathrm{~cm}$ tall and weighed $81 \mathrm{~kg}$. His overall health status was diminished (ECOG 1-2) and his nutritional status was normal.

In the axillary regions on both sides there were indolent and moveable lymph nodes measuring about $1.5 \mathrm{~cm}$ each. On the patient's back (about $20 \times 5 \mathrm{~cm})$, left $(5 \times 5 \mathrm{~cm})$ and right $(10 \times 12 \mathrm{~cm})$ thighs, as well as on the right flank $(5 \times 5 \mathrm{~cm})$, the right knee $(5 \times 5 \mathrm{~cm})$ and lower leg $(4 \times 6 \mathrm{~cm})$ there were large, partly ulcerous and necrotic, exophytic tumors on a dusky erythematous background (Figures 1,2).

\section{Diagnosis}

Laboratory tests-blood count: $\mathrm{Hb} 13.4 \mathrm{~g} / \mathrm{dl}$, thrombocytes 144/nl, leukocytes 6.4/nl, neutrophils $1.7 / \mathrm{nl}$, lymphocytes $0.6 / \mathrm{nl}$, eosinophils $0.06 / \mathrm{nl}$. Serum: CRP $14.1 \mathrm{mg} / \mathrm{l}, \mathrm{LDH}$ $258 \mathrm{U} / 1$.

Dermatohistopathology-Histopathology showed a dense dermal and subcutaneous infiltrate of medium-sized to large atypical lymphocytes with coarse chromatin (Figure 3). Numerous apoptotic cells and mitoses were detected. Immunohistochemistry showed tumor cell expression of CD43, CD56, TIA-1, but was negative for CD2, CD5, CD7, CD20, CD79a, CD30, granzyme B and beta F1. About $70 \%$ of neoplastic cells were positive for MIB1 and a small number were positive for CD3, CD4, and CD8. In sum, according to the WHO-EORTC classification, the results were consistent with gamma-delta T-cell lymphoma.

\section{Molecular pathology results, PCR amplification for the gamma chain of the T-} cell-receptor gene-No evidence of a clonal infiltrate.

Computed tomography neck/thorax/abdomen-Low-grade splenomegaly. No sign of lymphoma in neck, thorax, or abdominal regions.

\section{Therapy and outcome}

Our patient had already been diagnosed at another institution with malignant T-cell lymphoma of the skin (not further specified).

Although no clonal rearrangement was found for the T-cell-receptor gamma chain gene on PCR amplification, all other findings, especially in conjunction with clinical and histological appearances, were highly consistent with gamma-delta T-cell lymphoma according to the WHO-EORTC classification. Comprehensive staging showed no evidence of extracutaneous lymphoma manifestation.

Prior immunomodulatory therapy with interferon alpha at another institution had failed to stop progression of the disease. The patient was thus admitted to our hematological unit where specific chemotherapy was begun with gemcitabine/oxaliplatin/dexamethasone.

Therapy was well tolerated and two further cycles of the same treatment scheme were administered.

The disease later showed renewed signs of progression, even after three subsequent treatment cycles of methotrexate/asparaginase. We decided, along with the patient, to perform a curative, allogenic HLA-A- and HLA-DRB1-mismatch and blood-group identical peripheral blood stem cell transplant. 
The conditioning therapy, the transplantation itself, and the post-transplantation phase all proceeded without any significant complications.

More than 23 months later, the patient remains in complete clinical remission.

\section{Discussion}

Only 40 cases of primary cutaneous gamma-delta T-cell lymphoma (GD-TCL) have been reported worldwide [1]. GD-TCL was added in 2005 as a provisional entity to the WHOEORTC classification for cutaneous lymphomas [2], and since 2008 has been included in the WHO classification for myeloid and lymphatic neoplasias as a rare sub-type of primary cutaneous peripheral T-cell lymphoma [3]. Some lymphomas grouped together under this new category were previously classified as subcutaneous panniculitis-like T-cell lymphomas (SPTCL) with a gamma-delta T-cell receptor (GD-TCR) phenotype [4].

GD-TCL is a very rare form of lymphoma with a characteristic immunophenotype (CD3+, $\mathrm{CD} 2+, \mathrm{CD} 7+/-$, beta F1-). The majority of cells express neither CD4 nor CD8, although in isolated cases cells may be CD8 positive. Usually cells exhibit a clonal rearrangement for the T-cell receptor gamma chain gene [5]. This was not detected in our patient, however.

The histological appearances of GD-TCL can vary (epidermotropism, dermal and subcutaneous involvement), often in the same patient [6].

Epidermal and dermal infiltrates are often found with subcutaneous involvement, unlike in SPTCLs, which are characterized by exclusively or nearly exclusively subcutaneous infiltrates. GD-TCL with pronounced subcutaneous involvement may mimic other, much less malignant disorders such as lupus erythematosus profundus (LEP) in terms of clinical and also histopathological appearances. Repeat biopsies are often needed in order to make a correct diagnosis.

Cytological studies show medium-sized or large atypical lymphocytes with coarse chromatin. Occasionally there are also large, blastic cells with vesicular nuclei and prominent nucleoli. Numerous apoptoses are frequently found, often with vascular invasion.

Average age at onset of disease is 42 years; women are somewhat more frequently affected than men. Immunocompromise appears to be a significant predisposing factor [4].

Careful assessment of clinical, histopathological, immunohistochemical, and molecular biological findings is necessary to confirm the diagnosis. GD-TCL is a highly aggressive lymphoma which is characterized by an extreme resistance to polychemotherapy and radiotherapy. Median survival is 15 months [4]. In a recent review of 33 patients with GDTCL, 22 (66\%) deceased within five years of being diagnosed with the disease. Early diagnosis is essential and aggressive therapy is warranted in any patient diagnosed with the disease. Allogenic stem cell transplantation - as described in our patient - thus appears to be a promising future option for highly aggressive and, until now, lethal lymphomas such as GD-TCL. For other primary cutaneous T-cell lymphomas as well, such as treatmentrefractory variants of mycosis fungoides and Sézary syndrome, hematopoietic stem cell transplantation has been shown to significantly prolong the average length of survival [7].

\section{Conclusions for clinical practice}

Primary cutaneous gamma-delta T-cell lymphoma is an extremely rare and highly malignant lymphoma that has traditionally carried a grave prognosis given its pronounced resistance to treatment such as polychemotherapy and radiotherapy (average survival of 15 months after 
diagnosis). Prompt diagnosis is essential and treatment should be aggressive. Allogenic stem cell transplantation appears to be a promising future option for highly aggressive and, until now, lethal lymphomas such as GD-TCL.

\section{References}

1. Aguilera P, Mascaro JM, Martinez A. Cutaneous g/d T-cell lymphoma: A histopathologic mimicker of lupus erythematosus profundus (lupus panniculitis). J Am Acad Dermatol. 2007; 56:643-7. [PubMed: 17367613]

2. Willemze R, Jaffe ES, Burg G, Cerroni L, Berti E, Swerdlow SH, Ralfkiaer E, Chimenti S, DiazPerez JL, Duncan LM, Grange F, Harris NL, Kempf W, Kerl H, Kurrer M, Knobler R, Pimpinelli N, Sander C, Santucci M, Sterry W, Vermeer MH, Wechsler J, Shittaker S, Meijer CJ. WHOEORTC classification for cutaneous lymphomas. Blood. 2005; 105:3768-85. [PubMed: 15692063]

3. Swerdlow, SH.; Campo, E.; Harris, NL.; Jaffe, ES.; Pileri, SA.; Stein, H.; Thiele, J.; Vardiman, JW. WHO Classification of Tumours of haematopoietic and lymphoid tissues. IARC Press; Lyon: 2008. p. 302-3.

4. Ralfkiaer, E.; Willemze, R.; Meijer, CJLM.; Dummer, R.; Jaffe, ES. World Health Organization Classification of Tumours. IARC Press; Lyon: 2006. Primary Cutaneous Peripheral T-cell Lymphoma, unspecified. Pathology \& Genetics of skin tumours; p. 184-5.

5. Toro JR, Beaty M, Sorbara L, Turner ML, White J, Kingma DW, Raffeld M, Jaffe ES. Gamma delta T-cell lymphoma of the skin; a clinical, microscopic, and molecular study. Arch Dermatol. 2000; 136:1024-32. [PubMed: 10926739]

6. Yamaguchi M, Ohno T, Nakamine H. gamma delta T-cell lymphoma: a clinicopathologic study of 6 cases including extrahepatosplenic type. Int J Hematol. 1999; 69:186-95. [PubMed: 10222658]

7. Duarte RF, Schmitz N, Servitje O, Sureda A. Haematopoietic stem cell transplantation for patients with primary cutaneous T-cell lymphoma. Marrow Transplant. 2008; 41:597-604. 


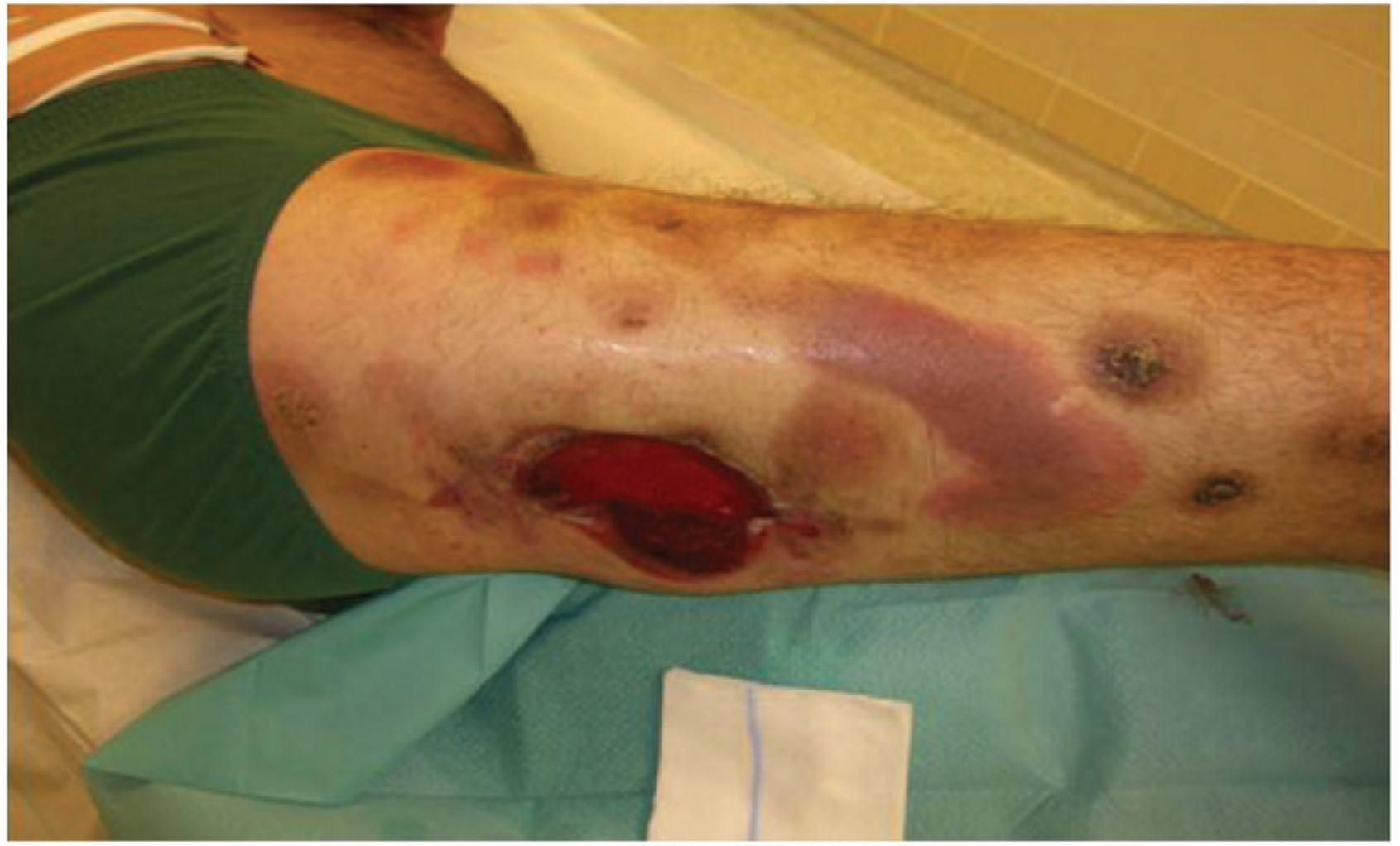

Figure 1.

Multiple tumorous and necrotic lesions on the lower extremities. 


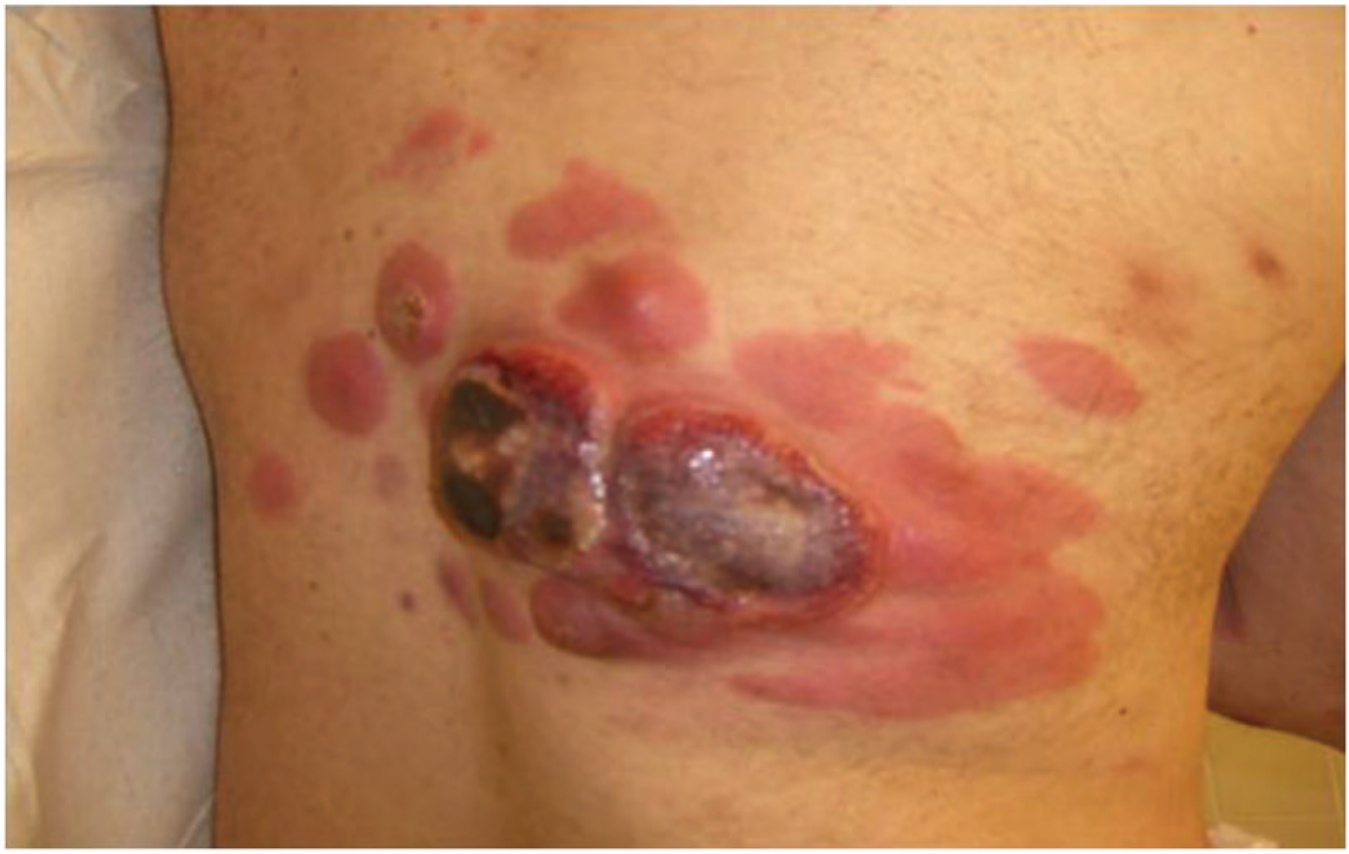

Figure 2.

Multiple tumorous and necrotic lesions on the trunk. 


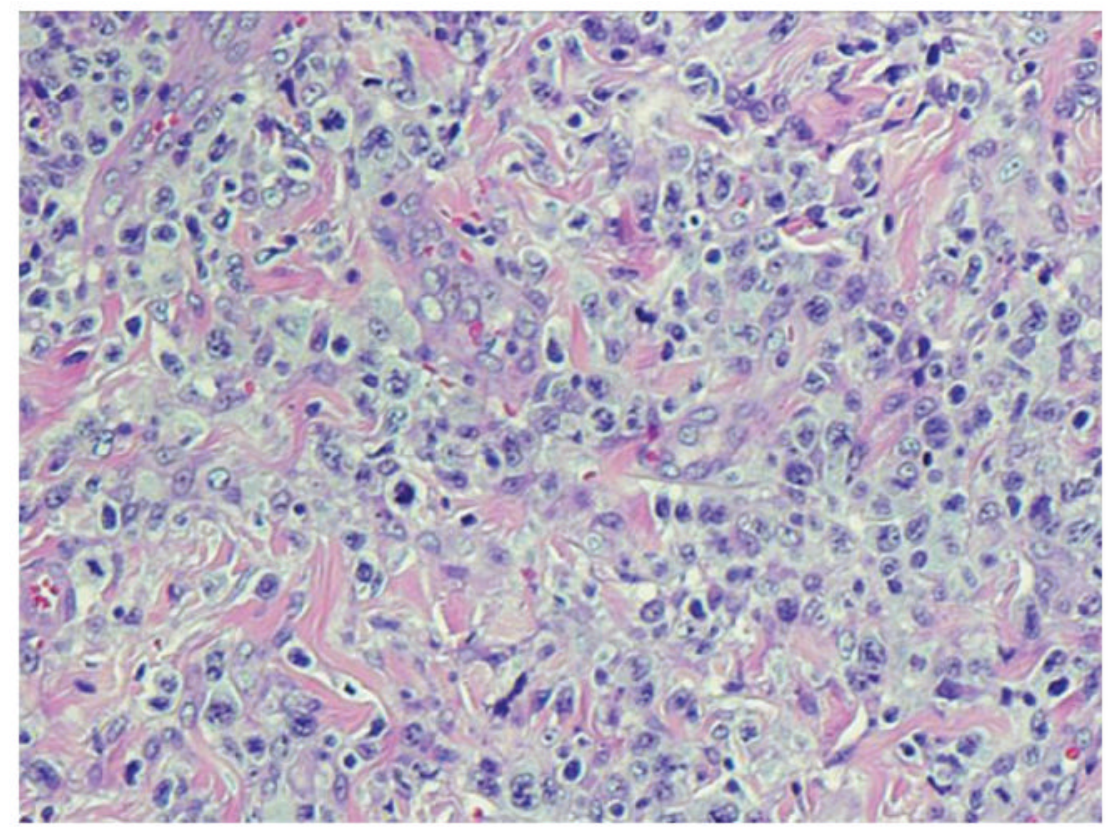

Figure 3.

Dense dermal infiltrate of atypical lymphocytes. 